\title{
PUPAL AGE AFFECTS EFFICACY OF IRRADIATION ON PAINTED APPLE MOTH TEIA ANARTOIDES
}

\author{
D.M. SUCKLING, R. PEDLEY and S.L. WEE \\ HortResearch, PO Box 51, Lincoln \\ Corresponding author: msuckling@hortresearch.co.nz
}

\begin{abstract}
The sterile insect technique has been deployed in Auckland, New Zealand, as part of the eradication programme of the Australian painted apple moth (Teia anartoides). Pupal age at irradiation was assessed as a factor potentially affecting both physical fitness (i.e. wing deformity) and sterility of emerging males. Males irradiated by the National Radiation Laboratory at $100 \mathrm{~Gy}$ at pupal ages of 2, 4, 6 and 8 days were emerged and mated with untreated females, and their egg production and hatch were assessed. Irradiation of pupae of different ages at $100 \mathrm{~Gy}$ did not affect the egg production at $F_{1}$ level, but younger pupae were significantly more susceptible to irradiation than older pupae. Sterility of $F_{1}$ increased with decreasing age. The optimal age for male irradiation and release was determined to be 6-day-old pupae, and this recommendation has been followed in the release programme in 2003/04.

Keywords: painted apple moth, sterile insect technique, irradiation, pupal age, sterility.
\end{abstract}

\section{INTRODUCTION}

The painted apple moth (PAM), Teia anartoides (Lepidoptera: Lymantriidae), is a native Australian pest accidentally introduced to New Zealand in 1999. The pest poses a much greater threat to New Zealand's horticulture, native forests and the natural estate compared to its minor pest status in Australia and is therefore of economic and ecological significance. Currently, this species is the target of an eradication programme operated by the Ministry of Agriculture and Forestry that includes the use of the Sterile Insect Technique (SIT), in the form of inherited sterility (Suckling 2003).

Inherited sterility is an autocidal pest control tactic that involves the release of incompletely sterile insects of adequate fitness to compete with wild males, which are effective at population suppression by the second generation post-treatment. The phenomenon of inherited sterility is today the preferred approach for SIT in Lepidoptera, as the development of dominant lethal genes in released individuals with reasonable fitness has been shown to provide much greater population suppression than with fully sterile but less fit insects (North 1975). Inherited sterility thus allows survival of a proportion of progeny from the irradiated insects, which then produce additional fully sterile offspring and a higher net level of population suppression. The survival and mating of sterile $\left(\mathrm{F}_{0}\right)$ insects thus multiplies the effective impact of released insects through the increased number of sterile $F_{1}$, with full mortality of progeny by $F_{2}$.

The identification of an effective dose of radiation that produces satisfactory inherited sterility of this species in conjunction with the mass releases of these sterile moths is contributing to both the eradication and the "back-up" long-term management programme objectives (Suckling et al. 2002). A successful SIT programme requires knowledge of the irradiation biology of the insect pest, including the most effective dosage and age of application, to minimise impacts on the fitness of the irradiated insects. Variation in emergence and apparent fitness after irradiation of male painted apple moth pupae on a weekly basis led to the need for a better understanding of these factors. Building on a previous report of an effective irradiation dose that gives inherited sterility (Suckling et 
al. 2002), this paper presents the effect of one irradiation dose (i.e. $100 \mathrm{~Gy}$ ) applied at different pupal ages on the fitness and sterility of the emerging insects. The frequency of wing deformity has been used as a measure of the effects of irradiation on male adults.

\section{Insect irradiation}

\section{MATERIALS AND METHODS}

Pupae of painted apple moth were sourced from the HortResearch Mt Albert Research Centre rearing colony in Auckland. Upon arrival, male pupae at different ages (i.e. 2, 4, 6 and 8 days old) were irradiated at the National Radiation Laboratory (NRL) using $1.25 \mathrm{MeV}$ gamma rays from a Cobalt ${ }^{60}$ source. Petri dishes $(9 \mathrm{~cm}$ diameter) were positioned on an aluminium scissor jack. The reference point for the irradiations was taken as at the geometrical centre of the stacked containers, which was set at a distance of $55 \mathrm{~cm}$ from the $\mathrm{Co}^{60}$ source. The entrance air kerma rate (measured free in air, with no back scatter in a $10 \times 10 \mathrm{~cm}$ field at $1 \mathrm{~m}$ ) was $19.9 \mathrm{mGy} / \mathrm{s}$. The radiation field size in the reference plane of the dishes was approximately $11 \times 11 \mathrm{~cm}$. The pupae were irradiated for $5015 \mathrm{~s}$ giving a dose (air kerma) of $100 \mathrm{~Gy}$.

\section{Adult wing deformity}

Male larvae undergo 5 instars (approximately 15 days at $25^{\circ} \mathrm{C}$ ) before pupation and another 8-10 days (at $25^{\circ} \mathrm{C}$ ) before emerging as adults. Male pupae of varying ages (2, 4, 6 and 8 days old) were irradiated at $100 \mathrm{~Gy}(\mathrm{n}=4 ; 20$ pupae/replicate) and allowed to emerge in a plastic cage lined with tissue. Two moistened dental rolls were placed inside to maintain humidity within the cage. Non-irradiated male pupae of the same age group ( $\mathrm{n}=4 ; 20$ pupae per replicate) were used as parallel controls. Males emerging with wing deformity were counted for each group. This measure was considered to be a better indicator of male fitness than total emergence, since males with deformed wings are unable to fly.

\section{$\mathrm{F}_{1}$ sterility}

Male pupae $\left(\mathrm{F}_{0}\right)$ irradiated at the four different ages above were individually paired with a female pupa in a disposable Petri dish $(6 \mathrm{~cm}$ diameter $)$. Emerged adults were allowed to mate. One week after adult emergence and mating, egg batches were collected from mated females, and allowed to hatch in a sealed $680 \mathrm{ml}$ pottle. After hatch had been completed, emerged larvae and unhatched eggs were counted and percentage hatch calculated.

\section{Statistical analysis}

For the wing deformity assessment, data obtained were normalized using a modified arcsine (Anscombe 1948) formula:

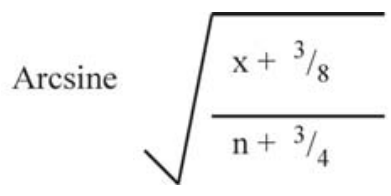

where $\mathrm{x}=$ number of males showing wing deformity and $\mathrm{n}=$ number of males subjected to analysis, i.e. $n=20$. Transformed data were then subjected to one-way analysis of variance (ANOVA) and means were separated by Tukey's test at $\alpha=0.05$.

Total egg production of females mated with $\mathrm{F}_{0}$ males emerging from pupae irradiated at different ages were analysed using one-way ANOVA at $\mathrm{P}=0.05$. Data obtained for egg hatch at different ages were subjected to Chi-Square analysis for homogeneity. Mean hatch of different age groups was then separated using Bonferroni Inequality test $(\mathrm{P}=0.05)$ (Rosner 1995). 


\section{Adult wing deformity}

\section{RESULTS}

Irradiation treatment at different pupal ages had a significant effect on the wing deformity of emerged adult males $(\mathrm{P}<0.001)$ (Fig. 1). Male pupae irradiated at 2 days old had the highest percentage of wing deformity $(55.7 \%)$ at adult male emergence. However, no significant differences were observed between pupae irradiated at 4,6 and 8 days old (27-32\%), and the control (21.7\%) (Fig. 1). There was no significant difference between the parallel controls of different pupal ages (i.e. 2-8 days old) $(\mathrm{P}>0.5)$.

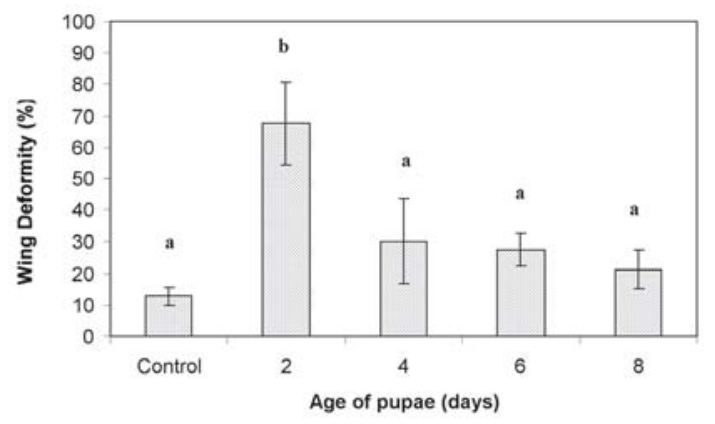

FIGURE 1: Mean percentage of $T$. anortoides males emerging with deformed wings, after exposure as male pupae at $2,4,6$ or 8 days old to $100 \mathrm{~Gy}$ irradiation $(n=4 ; 20$ pupae/replicate). Bars $(=S E)$ with the same letters are not significantly different (Tukey's Test, $P=0.05$ ). The control is the mean for parallel controls at each age.

\section{$\mathrm{F}_{1}$ sterility}

Egg production of females mated with males irradiated at different pupal ages was not significantly different from that of non-irradiated controls $(\mathrm{P}>0.05)$ (Table 1$)$. The mean egg hatch of the females mated with non-irradiated males was $63.7 \%$. However, the percentage of egg hatch (i.e. sterility) of the progeny of treated males was greatly reduced as the treatment age decreased (Table 1). Pupae irradiated at 2 days old had the lowest percentage of egg hatch. The highest egg hatch of the irradiated pupae was from pupae irradiated at 6 days old (Table 1). Male pupae irradiated at 8 days old showed a significantly lower percentage of egg hatch than the pupae irradiated at 6 days old.

TABLE 1: Mean egg production and egg hatch (\%) from females mated to male T. anortoides exposed to $100 \mathrm{~Gy}$ irradiation at pupal ages of $2,4,6$ or 8 days old.

\begin{tabular}{cccc}
\hline $\begin{array}{c}\text { Pupal age at } \\
\text { irradiation (days) }\end{array}$ & $\mathrm{n}$ & $\begin{array}{c}\text { Eggs laid per female } \\
\text { Mean }^{2} \pm \text { SE }\end{array}$ & $\begin{array}{c}\text { Egg hatch }(\%) \\
\operatorname{Mean}^{3} \pm \text { SD }\end{array}$ \\
\hline Control $^{1}$ & 155 & $230.3 \pm 9.7$ a & $63.7 \pm 0.25 \mathrm{a}$ \\
2 & 40 & $175.9 \pm 28.2$ a & $18.9 \pm 0.47 \mathrm{~d}$ \\
4 & 45 & $205.9 \pm 19.1$ a & $23.3 \pm 0.44 \mathrm{c}$ \\
6 & 45 & $222.7 \pm 20.8$ a & $35.1 \pm 0.48 \mathrm{~b}$ \\
8 & 20 & $275.4 \pm 29.9$ a & $23.9 \pm 0.57 \mathrm{c}$ \\
\hline
\end{tabular}

${ }^{1}$ Mean for parallel controls at each age.

${ }^{2,3}$ Means within the same column followed by different letters are significantly different at $\mathrm{P}=0.05$ ( ${ }^{2}$ One-way ANOVA; ${ }^{3}$ Bonferroni Inequality Test). 


\section{DISCUSSION}

Pupal age is a key irradiation variable affecting male sterility and fitness as indicated by lower emergence of males with deformed wings treated as 2-day-old pupae. The effect of irradiation showed a sharp decrease in sensitivity with age in this insect, confirming that somatic tissues lose their sensitivity to irradiation more rapidly with pupal age, as for other insects (Erdman 1960).

In two other Lepidoptera studied (Cydia pomonella and Helicoverpa armigera), egg production at the $\mathrm{F}_{1}$ level was significantly reduced with an increase in irradiation dosage $(<250 \mathrm{~Gy})$ when the female, rather than the male, was irradiated at late pupation period (Mansour 2002; Lu et al. 2002). In this study, when the same irradiation dosage (i.e. $100 \mathrm{~Gy}$ ) was applied to the male pupae of different ages, the total egg production of the inseminated females was not affected. This shows that the ability of mating and sperm transfer of the irradiated males was not affected by the $100 \mathrm{~Gy}$ treatment.

The egg hatch rates increased with the increase in male pupal age at irradiation. Greater egg mortality from irradiation of younger pupae would yield fewer $F_{1}$ adult males to mate with wild females and produce sterility at $\mathrm{F}_{2}$, which will have an overall impact on the success of the SIT programme.

Lower egg hatch was observed for pupae irradiated at 8 days old compared to the 6-day-old pupae. There is no direct explanation from this study or other similar studies that suggest pupae irradiation at age close to adult eclosion would cause higher sterility in the insect. However, the use of 8-day-old PAM pupae for irradiation is not advisable in the PAM SIT programme. At the optimal rearing temperature, i.e. $25^{\circ} \mathrm{C}$, the adult eclosion occurs at the $8^{\text {th }}$ day of the pupation period (A. Barrington, pers. comm.). There would also be problems with the administration of irradiation to 8-day-old pupae, due to emergence during handling procedures. In balancing between the sterility and fitness of the target insect, the 6-day-old male pupae would be the most suitable pupal age for irradiation treatment before being released into the field population.

The Sterile Male Technique is also currently being used to control codling moth (Cydia pomonella) in the Okenagan Valley of British Columbia (Bloem et al. 2001). A combination of mating disruption and mass release of sterile codling moth males has been investigated and results showed that inherited sterility was greater at $250 \mathrm{~Gy}$ - than $100 \mathrm{~Gy}$-irradiated males. However, moth dispersal distance was reduced, indicating the importance of balancing sterility and fitness (Bloem et al. 2001). Further work is continuing to assess the impact of irradiation on fitness of painted apple moths.

\section{ACKNOWLEDGMENTS}

This work was funded by MAF Biosecurity Authority and the Foundation for Research, Science and Technology. We would like to thank Anne Barrington (Mt Albert Research Centre, Auckland) for supply of insects, John Laban (National Radiation Laboratory) for irradiation services, and Hugh Gourlay (Landcare Research) for managing the quarantine facility.

\section{REFERENCES}

Anscombe, F.J. 1948: The Transformed of Poisson, Binomial and Negative Binomial Data. Biometrika 35: 246-254.

Bloem, S.; Bloem, K.A.; Carpenter, J.E; Calkins, C.O. 2001: Season-long releases of partially sterile moths for control of codling moth, Cydia pomonella (L.), (Lepidoptera: Tortricidae) in Washington apples. Environ. Entomol. 30: 763-769.

Erdman, H.E. 1960: Divergence between lethal doses and sterilizing doses of X-rays with progressive development in Habracon females. Nature 186: 254. 
Lu, D.G.; Liu, X.H.; Hu, J.G.; Wang, E.D.; He, Q.L.; Li, Y.J. 2002: Cotton bollworm, Helicoverpa armigera (Lepidoptera: Noctuidae): large scale rearing and the effect of gamma radiation on selected life history parameters of this pest in China. In: Proceedings of a final research co-ordination Meeting on Evaluation of Lepidoptera population suppression by radiation induced sterility 1998. Joint FAO/IAEA Division of Nuclear Techniques in Food and Agriculture. International Atomic Energy Agency, Austria. Pp. 23-27.

Mansour, M. 2002: Effects of gamma radiation on codling moth (Cydia pomonella, Lepidoptera: Tortricidae) fertility and reproductive behaviour. In: Proceedings of a final research co-ordination Meeting on Evaluation of Lepidoptera population suppression by radiation induced sterility 1998. Joint FAO/IAEA Division of Nuclear Techniques in Food and Agriculture. International Atomic Energy Agency, Austria. Pp. 61-68.

North, D.T. 1975: Inherited sterility in Lepidoptera. Ann. Rev. Entomol. 20: 167-182.

Rosner, B. 1995: Fundamentals of Biostatistics. Duxbury Press, Belmont, California, USA. 682 p.

Suckling, D.M.; Hackett, J.; Daly, J. 2002: Sterilisation of painted apple moth Teia anortoides (Lepidoptera: Lymantriidae) by irradiation. N. Z. Plant Prot. 55: 7-11.

Suckling, D.M. 2003: Applying the sterile insect technique for biosecurity: Benefits and constraints. N. Z. Plant Prot. 56: 21-26. 